\title{
DE LOS FÁCILES DICTADOS DEL MERCADO DE DEMANDA A LAS COMPLEJAS REDACCIONES DEL MERCADO DE OFERTA \\ - EL ÉXITO DESCANSA EN LA CADENA DE COMPROMISOS... ...“QUIERO SER LÍDER”
}

El compromiso entre las personas necesita de la confianza en la seguridad de que las otras personas, no fallarán ni en el fondo, ni en las formas, ni en los plazos y de que serán exactas en el cumplimiento de su parte que además es el enlace necesario para la cadena de compromisos. Si una persona no cumple su compromiso con exactitud rompiendo la confianza, pone en peligro el éxito que la CADENA DE COMPROMISOS se había propuesto, gracias al compromiso de cada eslabón de la cadena.

EL VALOR DEL COMPROMISO es clave en el éxito de cualquier logro sea de amistad, familiar, amoroso, deportivo, cultural, empresarial. Fuere cuál fuese el tipo de proyecto necesita de la suma de compromisos.

Cuando por falta de formación y/o de valores o por intereses deshonestos y poco transparentes y/o por desequilibrios y/o traiciones se rompe el compromiso, toda la organización entra en una situación de fracaso fruto de la desconfianza que se genera y si además quién no cumple su compromiso hace alarde de falta de honestidad y responsabilidad, no avisando a tiempo para rectificar y recuperar el error o riesgo y se explaya en excusas, mentiras y culpas ajenas, está además rompiendo la ética de la organización. Estemos atentos, porque estos rompedores de compromisos no pueden seguir dentro de una organización de compromisos.

EL VALOR DEL COMPROMISO como todos los valores lo escogemos libremente, a sabiendas de que su cumplimiento está por encima de ventajas, pillerías y comodidades, de que la honestidad, la transparencia y la lealtad a su cumplimiento nos aportarán a todos y a cada uno de los miembros del equipo, seguridad, confianza, complementariedad. En consecuencia, el logro perseguido, a sabiendas, y quiero reiterarlo por su importancia, que el romper el compromiso por falta de honestidad, transparencia y lealtad nos aportará desconfianza, desorden, desánimo y el fracaso.

\section{Domènec Biosca Vidal}

Presidente de EDUCATUR

BARCELONA - BUENOS AIRES - PALMA - GALICIA

AUTOR DE LA COLECCIÓN: LA NUEVA DIRECCIÓN COMERCIAL.

dbiosca@educatur.com

twitter: @dbiosca

www.educatur.com 